\section{Entre la esperanza y la desilusión: memorias de la lucha por la democracia en las poblaciones de Santiago (1983-1988)}

From hope to disappointment: memories of the struggle for democracy in the shantytown of Santiago (1983-1988)

\section{JuAn RADIC-VEgA *}

\section{Resumen}

El artículo propone contrastar las formas y contenidos en que se escribió la historia oficial de la lucha por la democracia, con la memoria de dos pobladores de Santiago. A partir de los recuerdos de una mujer comprometida con la organización social y un joven militante socialista, pretendemos rescatar cómo sus memorias se conectan y/o entran en tensión con las memorias colectivas

Agradezco a Beatriz y Jaime por recibirme y confiarme aspectos tan íntimos y difíciles de sus historias.

** Instituto de Humanidades, Academia de Humanismo Cristiano; Investigador Universidad Autónoma de Madrid, jradicv@academia. docentes.cl sobre esta época, analizando los significados que otorgan a su lucha por la democracia, la esperanza que vuelcan en dicho proceso y la desafección que les invade cuando se instala un modo restringido de democracia. Evidenciamos la tensión latente entre los imaginarios democráticos que subyacen entre los pobladores, con el modelo que finalmente impuesto. Nos interesa atestiguar la fractura social vivida por la oposición en su tránsito hacia la democracia, cisura que marcó la construcción de la democracia.

Palabras clave: Lucha por la democracia, memorias poblacionales, memoria.

\begin{abstract}
The paper aims to contrast the forms and contents in which the official history of the fight for democracy was written, by using the memoirs of two Santiago residents. Through the remembrance of a woman committed to the social organization and those of a young socialist militant, we seek to rescue the way in which their memories connect and/or clash with the collective memory of that period, analyzing the meaning that they assign to their fight for democracy, the hope they instill in that process, and of disaffection that pervades them when they install a limited mode of democracy. We show the latent tension between the democratic imaginaries that lie underneath the pobladores and the model that was ultimately established. Our goal is to attest the social rupture that the opposition suffered on its way to democracy, a rupture that also defined the way in which the Chilean democratic system was built.
\end{abstract}

Key words: Movements of Pobladores, struggle for democracy, memory 


\section{Introducción}

La relación entre historia y memoria en el mundo contemporáneo, se ha visto permanentemente tensada por los modos en que la historiografía, y las propias sociedades, interpretan y revisitan su pasado reciente. Las formas de enunciar y escribir, así como el (re)significado otorgado al acontecimiento que se rememora, son entre muchos otros, aspectos fundamentales de esta compleja interrelación que conecta al conocimiento historiográfico con la experiencia vivida de los testigos, sus testimonios, silencios y olvidos, en suma, con la subjetividad que constituye la reproducción de los sentidos de ese pasado que se evoca individual y colectivamente (Cuesta 2008). El fenómeno adquiere mayor trascendencia en contextos difíciles, con situaciones traumáticas de por medio que representan una ruptura para la sociedad que los experimenta (Perotin Dumon 2007), trastocando el propio sentido del tiempo histórico. Su magnitud, en efecto, provoca una verdadera fisura epistémica; no sólo en el sentido en que nada volvió a ser como era -a ser pensado ni dicho como antes-, sino en el propio enclave temporal en que se constituyen para sus sociedades (Garcés 2005: 15).

En ese orden, las dictaduras latinoamericanas de Seguridad Nacional significaron un cambio en la "escenificación del tiempo histórico" (Subercaseaux 2010: 111), esto es, una tranformación radical en la manera que las sociedades, a través de un conjunto de representaciones y narraciones e imágenes, experimentaron su propia vivencia colectiva del tiempo. Entendiendo que esta trama en que se manifiesta la cultura de una sociedad es un campo permanentemente en disputa, identificamos las coordenadas generales desde las que se elaboraron los relatos sobre ese 'momento' de la historia latinoamericana, constituyendo un punto de ruptura y división social que se ha prolongado en el tiempo a través de la memoria.

El caso chileno ha visto en el golpe de Estado de 1973 y la "dictadura revolucionaria" que le siguió (Moulian 1997), un nodo central en el cuál la memoria se ha enquistado; marcando, proyectando, y (re)significando el tiempo presente. De igual manera, el presente ha ido redefiniendo los sentidos y representaciones del aquel traumático acontecimiento. Esta dualidad, ha propiciado una interrelación temporal compleja entre pasado y presente, siempre atizada por el dolor, el conflicto y la violencia que representó para los chilenos esta experiencia. Dicho de otro modo, el tiempo de la dictadura cívico-militar, con toda la carga emotiva que representó para sus ciudadanos, sus horrores, batallas, transformaciones, conmemoraciones, silencios y olvidos, se ha erigido en un punto de inflexión de nuestra historia presente.

El estudio de la memoria del trauma que representó el golpede Estado de 1973y su legado -una dictadura terrorista y refundacional - han abierto la puerta al conocimiento de "mentes y corazones" de lo que significó la experiencia autoritaria para los chilenos (Stern, 2009: 22). En ese sentido, se puede profundizar sobre aquellos aspectos menos visibles múltiples y diversos - en la construcción de las subjetividades, y el modo que se incorporan a una memoria más amplia de algún sector específico de la sociedad. Traspasando la superficie, se observan modos de expresión, de ser, que dan forma a un universo de sentido del mundo que les rodea. Miedos, aprensiones, pero también esperanzas, y anhelos que a través de 
la memoria transfieren al acontecimiento pasado la representación simbólica de algo más que el hecho en sí, mostrándonos -fragmentariamente al menos - procesos articulados y subterráneos que conforman parte de los imaginarios de los sujetos que rememoran (Portelli, 1989: 5). De esta forma, podemos entrever aspectos íntimos que marcan y definen a la memoria y por qué entra conflicto con otras representaciones existentes en la sociedad.

En nuestro caso, entendemos que las experiencias personales analizadas, simbolizan un modo concreto de sentir que se expresó mayoritariamente entre los habitantes organizados de las poblaciones de Santiago. Un símbolo de su experiencia radical de lucha contra la dictadura. Por un lado, una mujer comprometida con los grupos de base de la población, estrechamente vinculados a la iglesia católica en el sector sur de la capital. Por otro, un joven militante socialista, que vive la clandestinidad al amparo de su barrio para luchar por la democracia a través de la acción política. Ambos, representan íconos de la lucha por la democracia de la década de los 80' (Stern, 2013: 331). Analizando dichas subjetividades, creemos poder establecer un nexo entre estas experiencias personales y su proyección a la memoria colectiva de un sector de la sociedad.

Desde esta perspectiva, nos interesa estudiar el presente del pasado -la memoria- y cómo se ha constituido en dos actores emblemáticos de la lucha por la democracia. Observar en el presente un aspecto del pasado aún vivo, nos permite recorrer los caminos por los cuales esa representación del pasado se ha construido (Bianchini 2012: 30), comprendiendo así el devenir de esta construcción en la memoria de dos sujetos (sus incoherencias, transformaciones, selecciones y omisiones), haciéndolo desde una propuesta hermenéutica, es decir, que los recoge e interpreta en un contexto determinado. En este caso, elaborando un relato de cómo y por qué estos dos actores sociales, símbolos de la lucha popular por la democracia, se posicionan del modo que lo hacen respecto a ese momento histórico y sus proyecciones al tiempo presente desde el que se pronuncian.

Nuestra hipótesis plantea que, al menos en un sector de la población, estos sentimientos se relacionan con la desilusión que trajo el modo en que se construyó y evolucionó el sistema político en el tiempo de la postdictadura. Más en concreto, somos de la idea que el proceso que representó la lucha social, política y electoral, generó un alto grado de expectativas en la futura democracia, sobre todo en los sectores populares organizados. Éstos, proyectaron sus antiguos imaginarios democráticos -previos al golpe de Estado- donde la participación, la comunidad y un Estado comprometido con la justicia social, conformaban parte fundamental del ideario popular. La ausencia de estos valores en la nueva democracia, así como la progresiva desmovilización incentivada por el gobierno democrático, alejaron y desafectaron a estos protagonistas en la batalla contra la dictadura.

\section{Las protestas nacionales y la lucha por la democracia (1983-1988)}

Cuando Rodolfo Seguel llamó a los chilenos a adherir al paro nacional convocado por la CTC para el 11 de mayo de 1983, fue enfático en señalar que las dificultades que sacudían a los chilenos no eran un tema coyuntural ni circunscritas a un mal momento de la economía. 
Eran, más bien, un problema de fondo, estructural, fundamentalmente provocado por un modelo construido desde el mismo 11 de septiembre de 1973, y que se encontraba al borde del colapso. Esta, fue la interpretación de la inmensa mayoría de opositores a Pinochet. Es más, con el paso de los meses y la realización de otras dos protestas con resultado aún más exitoso en cuanto a impacto y masividad ${ }^{1}$, el grueso de la sociedad expresaba la urgencia del momento y la necesidad de llevar adelante cambios de fondo, mientras los partidos se reposicionaban creando una "arena política de facto" que los llevó a asumir, en adelante, la conducción de la lucha por la democracia (Lünecke 2000).

Visto en retrospectiva, las diferencias tácticas de ese primer momento respecto a la efectividad de la forma (el paro se convirtió en protesta ya que implicaba arriesgar la fuente de ingreso en momentos que el desempleo bordeaba el 30\%), evidenciaron divergencias profundas al interior de la oposición, respecto a los fundamentos que definirían al proyecto político que comenzaba a desarrollarse. En ese sentido, visibilizó la renuencia y aprensión de un sector de la oposición a la movilización social, a su papel y protagonismo en "lo político"2, quizás aún influenciada por los fantasmas que representó la acción colectiva durante la Unidad popular ${ }^{3}$.

Las tres primeras protestas tuvieron un carácter festivo y fueron transversales, generando la percepción de que sería imposible acallarlas. Si la primera fue fundamentalmente en Santiago, las siguientes se extendieron por todo el país. Para una visión sinóptica de las protestas ver (Cavallo et. al. 1997). Para una visión analítica, ver (Moulian 1997)

2 Seguimos aquí a Mouffe (2007: 16) respecto a la distinción entre la política como la práctica habitual de la institucionalidad, de lo político, como aquello que instituye a la sociedad.

3 Riquelme (2009) señala que las discrepancias emergieron desde el mismo llamado a protestar, atisbando las diferencias que marcarían el proceso en la oposición.
Empoderar a las masas, en otras palabras, resultaba sumamente riesgoso. Ante la presión de la Democracia Cristiana (DC), el paro se convirtió en protesta. $Y$ aunque el formato resultó adecuado al extender masivamente el afán por protestar, desencadenó una auténtica "catarsis" colectiva en la sociedad chilena (Moulian 1997: 291), que escapó a cualquier planificación y expectativa, incluidos los más optimistas (Aylwin 1998; Corvalán 1983).

Los repertorios de acción, en efecto, propiciaron la participación libre de las personas, que pudieron adecuarse a sus posibilidades sin necesidad de arriesgarse innecesariamente. El clamor popular retumbó con el caceroleo y los gritos de "Y va caer" emocionando, y conectando a la gente. En las poblaciones, el efecto liberador condujo a irrumpir en las calles y expresarse sin importar las consecuencias ${ }^{4}$. La familiaridad del lugar, propició la complicidad entre vecinos, incentivando la extensión del fenómeno hacia otros menos movilizados 5 . El éxito provocó un cambio sustancial en la subjetividad de las personas que, a partir de ahí, decidieron de manera activa desafiar al régimen. Algunos lo hicieron con el simple hecho de discutir de política o comprar una revista opositora. Otros, sin embargo, dieron pasos agigantados hacia la rebelión civil; mujeres y jóvenes pobladores, principalmente, se reapropiaron del espacio público otorgándole nuevos sentidos -opuestos al oficial- y, a través de variadas formas, visibilizaron las redes que se venían construyendo en los márgenes paraestatales (Salazar 2006: 302).

Para los efectos de la represión ver: Arzobispado de Santiago,
Informe Mensual, mayo 1983 (CD y AVS).
Tarrow (2009: 202), caracteriza este fenómeno como "ciclos de acción colectiva". 
La oposición situó la crisis económica como principaldesencadenantedelaexpresión popular (Manifiesto Democrático, 1983), insistiendo que la transversalidad social del malestar era fruto de diez años de dictadura: sin libertades, de persecución política y violencia; atomización y desarticulación social. Diez años de miseria, abandono y pobreza para los sectores más desvalidos. Diez años, en definitiva, en que "la institucionalidad democrática se había destruido por completo, producto de un modelo" (Lagos 1983: 4). Aquel sistema que precisamente simbolizaba los principios de la dictadura cívico militar que encabezaba el general Pinochet.

Este sentimiento propició que, adecuando las formas de expresión, las sinergias convergieran en el conjunto de la sociedad. Sin pensar igual del pasado, del régimen y sus principios, e incluso sobre el futuro (Corvalán 1983), la sociedad civil se manifestaba contra una realidad de opresión, crisis y violencia, de la mano de distintos referentes sociopolíticos exigiendo democracia (Valdés Subercaseaux 1983). En ese orden, fueron las bases sociales de la oposición las que mostraron el camino de la unidad y el trabajo conjunto, proyectando en el imaginario colectivo la posibilidad cierta de derrocar al régimen. La idea de ingobernabilidad se apoderó de la amplia mayoría de opositores, que entendió las protestas como el camino para alcanzar la democracia a través de ese "intersticio" que identifica Riquelme (2009: 128), entre la acción comprometida en el espacio público y la no violencia armada.

Pero la masiva expresión social manifestada en las primeras protestas cambió con el paso de los meses. Una vez asentados los partidos en el nuevo escenario político, y ejecutadas las estrategias del régimen para controlar la movilización y dividir a la disidencia, las protestas perdieron el carácter festivo, masivo y "espontáneo" que habían presentado en los primeros meses de 1983 (Campero 1986), para convertirse en un escenario peligroso y elitizado, exclusivo para los dispuestos a ejercer o padecer la violencia que empezaba a generalizarse. Estas dinámicas, para fines de 1984, habían marginado a los sectores medios y a una masa asustada por la represión dictatorial, mientras la oposición partidista -dividida entre Alianza Democrática y Movimiento Democrático Popular que confrontaba a democratacristianos y comunistas - pugnaba por establecer el camino hacia la democracia y el papel que le cabía a la acción colectiva en él. De este modo, las protestas se "rutinizaron" (Moulian 1997: 317), permitiendo al régimen retomar el control e imponer el Estado de sitio en noviembre de 1984.

De ahí en más la movilización social se convirtió en una herramienta de presión política eficaz pero poco percibida como el canal de participación que tuvieron los ciudadanos para expresarse políticamente. Las protestas que siguieron entre 1985 y 1986, comprobaron esa dualidad: entre expresión popular de masas rebeldes y demandantes de una nueva democracia, por una parte, y herramienta política para presionar y modificar el calendario trazado por la Constitución, por otra.

Queremos enfatizar, por tanto, que la cuestión táctica respecto al rol de la movilización social en la lucha por la democracia, se constituyó en un nodo central de la discusión estratégica de la oposición, situando el debate no sólo en torno a la legitimidad de la violencia contestataria como mecanismo de acción sino, soslayadamente, simbolizando el papel que la dirigencia opositora 
asignaba a la ciudadanía en la construcción de estrategias políticas. En este debate se observan los fundamentos básicos que constituyeron el pensamiento político y la idea de democracia subyacente de los distintos grupos opositores a Pinochet. Ideas y argumentos que se fueron elaborando paulatinamente durante este periodo. Es decir, un modo específico de comprender el sistema democrático que debía y podía implementarse. Representaciones que evidentemente se proyectaron a la transición democrática.

De esta manera, las concepciones respecto a la movilización social, definieron el modo en que se incorporaría la participación ciudadana en el proceso final de lucha por la democracia y la transición política que le siguión. Estos fundamentos, pilares de la acción opositora, marcaron indefectiblemente un modo de pensar y hacer, que resultó un emblema de la acción política postdictatorial. La vía de la transacción, la inserción en las normas de la dictadura y la marginación dela movilización social en la política, resultaron ser un momento constituyente en la oposición moderada al régimen, imprimiendo un sello específico a las formas de pensar, imaginar y hacer política. Por su parte, el papel asignado a la acción colectiva, también definió la memoria de los dirigentes de la transición que relegaron a un segundo plano su relevancia respecto al significado que estas expresiones encarnaban, convirtiéndolas en mero antecedente del éxito político que representó el triunfo por la vía electoral (Álvarez 2001: 193).

La "rebelión popular" (Salazar 2006: 295) que encarnaron las protestas nacionales, se produjo

La detención de Pinochet, en 1998, abrió un nuevo escenario político en que la sociedad logró permear y cuestionar las lógicas que impuso la transición. en una sociedad que presentaba sus primeros atisbos de cambio, de acuerdo a la profunda reestructuración social que el régimen había impulsado en torno a las relaciones sociales, las estructuras económicas y el sistema político. Es más, Chile se encontraba en pleno proceso de consolidación de la nueva lógica -autoritaria en lo político y neoliberal en lo socioeconómico y cultural - que implicó un cambio sustancial en las relaciones entre el Estado y la sociedad (Guillaudat y Mouterde 1997). Este hecho, resultó decisivo en el paulatino abandono a los sectores populares, una vez que la dictadura logró retomar la iniciativa política. Tanto la clase media atemorizada por la violencia e interesada en satisfacer sus intereses sectoriales en un nuevo escenario económico, como las cúpulas partidistas moderadas, limitaron a la acción colectiva como herramienta eficaz de presión para el término de la dictadura, desconociendo su valor en sí mismo como aunténtico sentir político de los sectores populares organizados.

Pese a ello, al interior de la DC se fraguaba desde hacía tiempo - la idea de someterse a la Constitución de 1980 para, desde dentro, derrotar al régimen (Boeninger, 1997). Como táctica, esta perspectiva pragmática presentó una mirada acertiva de la situación a la que se efrentaban, máxime cuando durante 1986, la violencia fracturó de manera decisiva a la movilización social y la oposición. Sin embargo, posiblitaron el giro defintivo hacia la vía institucional-autoritaria, responsable del diseño de un modelo resitringido y controlado de participación política, limitando la intervención de la sociedad en la nueva democracia al exclusivo acto electoral. El hecho marcó profundamente a los sectores poulares organizados y el modo que interpretaron el proceso y sus efectos en la futura democracia. 


\section{Memorias disidentes en las poblaciones de Santiago}

\subsection{Mujer, pobladora y activista social: Beatriz y la nostalgia por el compromiso de la comunidad ${ }^{7}$}

Beatriz es una mujer estrechamente ligada a la historia social de Chile de la segunda mitad del siglo XX. Como muchas santiaguinas habitantes de la periferia, se fue haciendo un espacio en la vida pública a través del barrio, pese a las dificultades que ha representado históricamente ser mujer y pobre en América Latina. No obstante, su esfuerzo, convicción e inquietud permanente, la convirtieron en un referente para otras mujeres y para la comunidad en general. La Bety, como la conocen los 'adrianinos', sigue siendo hoy en día una figura reconocida, respetada y también criticada por los vecinos más antiguos de la población.

Beatriz llegó a Santa Adriana a través de la toma ilegal de terrenos pese a estar inscrita en CORVI. Con sus dos hijos, embarazada de siete meses y a escondidas de su padre y su marido, se instaló en los sitios que se estaban habilitando en la ex Chacra Santa Adriana. Corría el año 1960, momento en que el grave problema de la vivienda marcaba esta etapa de la historia de Chile (Garcés 2002). Acceder a la vivienda a través de la acción directa, representaba la pobreza en su máxima expresión, de acuerdo a los imaginarios existentes en la sociedad chilena, y que algunos sectores populares reproducían de forma instintiva en ese afán de insertarse definitivamente en los cánones

Las entrevistas a Beatriz fueron 4, se realizaron entre octubre de 2011 y diciembre de 2014. También extrajimos sus testimonios de reuniones grupales junto a otros vecinos de la población Santa Adriana realizadas en 2015 , con motivos de la investigación de doctorado del autor. culturales dispuestos por la élite. Sin embargo, esta procedencia le permitió forjar profundas relaciones con los vecinos que provenían de 'la toma' y que tenían una potente estructura organizativa. El trabajo conjunto abocado a construir el hogar, sus calles y espacios comunes, propició lazos y afectos que conectaron a sus miembros bajo un fuerte sentido de comunidad; una identidad común.

\begin{abstract}
Las necesidades que tuvimos nos unificó. Como oyente en el Hospital San Borja para técnico auxiliar, ayudó a la comunidad con sus conocimientos: "A veces me venían a buscar a las tres o cuatro de la mañana (...). Y como yo tenía el conocimiento (...), había que hacerlo nomás. Así era la gente al principio. Así tenía que ser de solidaria la gente ${ }^{8}$.
\end{abstract}

La condición de pobreza se veía fuertemente complementada por la de mujer: la emancipación seguía siendo un tema pendiente en un país que reproducía las bases de un sistema patriarcal donde la mujer mantenía su subordinación al hombre (Valdés 1987: 5). Pese a sus inquietudes, Beatriz siguió colaborando con la comunidad desde la esfera doméstica, aún inconsciente del papel político que representaba en realidad su trabajo: "Yo era bien ignorante en lo que es política. Como todas las mujeres de nuestra generación (...). No nos dábamos ese permiso (...) por ser sumisas también. Por ser muy ingenuas, hasta la vejez". Sólo el golpe de Estado con su carga de violencia y horror, y las profundas consecuencias que provocaron las transformaciones estructurales implementadas por la dictadura, la hicieron tomar consciencia ${ }^{9}$.

El golpe, en efecto, representó un cambio abrupto y violento en la vida de los pobladores. La incredulidad, el miedo y la resignación,

Entrevista realizada por el autor en noviembre de 2011.

9 Entrevista realizada por el autor en noviembre de 2011. 
marcaron para siempre el pensar de Beatriz, significando, al mismo tiempo, un auténtico despertar: "Yo no podía entender porque había tanta gente en las calles disparando a las casas", señala en referencia al sitio -terrestre y aéreoque se realizó a todo el sector sur de la capital el 11 de septiembre de 1973 y los meses que siguieron al golpe ${ }^{10}$. Fueron, no obstante, los cambios a más largo plazo los que modificaron para siempre su vida, remeciendo su consciencia y transformando el modo de parapetarse y encarar las situaciones que le tocaba vivir. Con la dictadura, se iniciaron dos procesos paralelos que iban a afectar directamente su entorno; la profunda transformación social y económica que significaron las políticas librecambistas, por una parte, y la persecución y exclusión a la que fueron sometidos los pobladores -considerados potencial foco de subversión, dada su cercanía con el gobierno de la UP - por otra (Bruey 2009: 20). Ambos elementos agudizaron dramaticamente el desamparo propiciado por el incentivo de la desarticulación social y el abandono del Estado en su papel asistencial.

El contexto de violencia, pobreza y exclusión, empujaron a Beatriz a salir de su casa y participar de la desesperada reorganización del tejido social por la imperiosa necesidad de subsistir:

Cuando empecé a ver esta realidad (...) yo necesitaba respuestas de porqué ocurrían estas cosas. Yo tenía que salir de alguna manera. Salir y ver y entender. Tenía que saber lo que era lo social. (...) Y todo eso fui buscando. Y me fui metiendo y fui encontrando respuesta. $Y$ a través de eso, se construyó más férrea la rebeldía y la fortaleza en uno ${ }^{11}$.

10 Según la Comisión Nacional de Verdad y Reconciliación (CNVyR), hubo una víctima fatal en Santa Adriana producida por los disparos realizado por la Fuerza Aérea -a cargo del sector- a través de un helicóptero. (CNVyR). Según los vecinos y el recuerdo de Beatriz, existieron 5 muertos. (Colectivo Las Patotas, en Garcés y Villela 2012).

11 Entrevista realizada por el autor en noviembre de 2011.
En Santa Adriana, al igual que en la mayoría de las poblaciones de Santiago, la rearticulación del tejido social comenzó lentamente, a partir de 1974 (Valdés, 1986), cuando los efectos de las políticas de shock sacudían dramáticamente las economías familiares. La decisión de las iglesias por asistir a las víctimas de la dictadura -víctimas políticas y económicas(Bastías, 2013), propiciaron que la parroquia se convirtiera en un centro neurálgico del trabajo y la organización social que, más tarde, dio paso a la discusión y la acción política. En un comienzo, la parroquia formó algunos comedores infantiles para paliar el hambre, iniciativas que se mantuvieron funcionales hasta el año 1977, aproximadamente ${ }^{12}$. Beatriz participó de ellos, observando que las necesidades involucraban a familias completas, no sólo a los niños.

\begin{abstract}
Después de insistir harto, salió de parte de Cáritas la ayuda. 700 familias comiendo de las ollas comunes y el bar lácteo. En distintos sectores. Primero tuvimos que enseñarles a las señoras a pedir leña y ahí salía yo con una carta del cura. Porque a la gente le daba vergüenza. Vergüenza abrir su puerta y que otros vieran su realidad, sus necesidades, sus penas ${ }^{13}$.
\end{abstract}

Como bien retrata Beatriz, de los comedores infantiles se dio el paso a las Ollas Comunes que diversificaron la labor social ampliando los quehaceres, de manera de involucrar a la comunidad al completo y responder a las crecientes necesidades. En ese sentido, las ollas comunes fueron mucho más que una "radiografía de la pobreza"; resultaron más bien un espacio de organización popular, asentado territorialmente y cuyo objetivo por la subsistencia se amparaba en el trabajo colectivo de sus miembros (Hardy 1986: 25).

Ver Informe sobre Comedores Populares de la Vicaría de la Solidaridad. Evaluación y conclusiones. 1982. CDyAVS.

13 Entrevista realizada por el autor, noviembre de 2011. 
La dedicación exclusiva $-y$ ad honoremal trabajo comunitario de Beatriz, vino, sin embargo, cuando la hermana Luz fundó un grupo de salud a mediados del año 79. En un principio, ocupaban una salita contigua a la parroquia. Pero la dramática situación requirió que los servicios se extendieran. Madres embarazadas con principio de desnutrición, la reaparición de todo tipo de enfermedades, la empujaron junto a otras mujeres a demandar mayor ayuda a la iglesia y extender las tareas del grupo. "la salud fue lo primero que echaron a perder (...). Los números no alcanzaban en el poli. Se fuera a la hora que se fuera, no alcanzaban los números. Entonces estaba la salita de atención de la parroquia"14.

La situación extrema experimentada en las poblaciones, tornó urgente ampliar los espacios de cooperación. Así, al amparo del Decanato y del trabajo comprometido de las bases a través del colectivo Caro Ochagavía, se creó un grupo de salud potente que amplió sus tareas y cobertura, pero, por sobre todo, fue trazando su propio camino de acuerdo asus necesidades como grupo y los de la comunidad en general. Este proceso de formación y liberación confluyó con las nuevas orientaciones que impulsaron las organizaciones intermedias, fundamentalmente a través de sus profesionales, críticos del asistencialismo paternalista que había caracterizado a las últimas décadas. Esto, llevó a incentivar la concientización, autonomía y politización de los actores sociales para que fueran ellos mismos los que establecieran los modos de su participación en la sociedad (Bastías 2013: 98).

Este proceso incentivó el "despertar" de Beatriz, esa efectiva liberación que permitió a ella y a

\footnotetext{
Entrevista realizada por el autor, diciembre 2011.
}

su grupo comprender de manera profunda y reflexiva la realidad que les tocaba vivir. "Realmente descubrí muchas cosas que yo no había descubierto en mis treinta tantos años antes"15. Este contexto favoreció que Beatriz y el grupo de mujeres del Decanato, ampliaran su aprendizaje, su perspectiva y adquirieran mayor conciencia política de su realidad como mujeres pobladoras. Fue así como de la salud dieron el salto a la mujer, creando el Frente de Mujeres;

\begin{abstract}
Y al hablar de mujer, hablábamos de todo. (...) el derecho a estar sano, a la atención de la salud, el derecho a la educación, el derecho a la recreación, al trabajo a la vivienda. (...). Y a todo eso le pegábamos. Porque acá había una buena coordinación con toda la gente de Santa Olga, Clara Estrella, Santa Adriana (...) donde estaba el cuerpo de mujeres. (...) y nos organizábamos como decanato. Pero el decanato no delineaba el trabajo social independiente de la parroquia. Teníamos que organizarnos como grupo autónomo-social. Por eso creamos el Frente de la Mujer, y dentro de ese frente estaba el frente de la vivienda, el frente de los sindicalistas de trabajo, y todo estaba aglutinado en el Caro-Ochagavía ${ }^{16}$.
\end{abstract}

El Frente de Mujeres Pobladoras favoreció la ampliación de la participación, haciéndose necesario propiciar la intimidad -forjar lazos y confianzas - y profundizar en el trabajo personal para fortalecer la dignidad de las participantes: como mujeres, pobladoras, ciudadanas.

\begin{abstract}
Yo creo que la mujer tomó consistencia dentro de su... se empoderó de sí misma, para poder defender el derecho de sus cabros a comer. Porque tuvo aprender pa' trabajar y tuvo que pelear pa' trabajar. Y para eso tuvimos también que capacitarnos. Capacitarnos en lo psicológico. Nos enseñaron de psiquiatría y todas esas cosas. Para poder lograr entender el porqué de las cosas, de las situaciones ${ }^{17}$.
\end{abstract}

\footnotetext{
15 Entrevista realizada por el autor diciembre 2011. En realidad, Beatriz tenía más de cuarenta años en la década de 1980.

16 Entrevista realizada por el autor diciembre 2011.

17 Entrevista realizada por el autor en noviembre 2012.
} 
Fue, en efecto, en el taller donde encontraron los espacios de intimidad y complicidad con las demás mujeres. En ese sentido, si las actividades organizativas de orden económico tenían un fin concreto de generar recursos o las artístico/culturales un carácter recreativoformativo, a su vez, permitían estrechar lazos y generar espacios de confianza en el cual muchas mujeres lograron desenvolverse y liberarse del yugo normativo que representaba su vida, supeditada exclusivamente al hogar. Las ideas de liberación y participación, entonces, fueron convirtiéndose en un aspecto constitutivo de este tipo de organizaciones, del perfil de sus actores, sus principios, anhelos e idearios.

Tuvimos la posibilidad de preocuparnos de la gran mayoría de nuestras necesidades. Y lo hacíamos entre todas. (...) Esa es la comunidad que debiese de existir. Esa es la comunidad más democrática, pienso yo. Porque si no, nunca vamos a tener democracia de verdad ${ }^{18}$.

Parte del inmenso trabajo comunitario realizado durante este periodo, salió a luz pública con las protestas nacionales (1983-1986). Las comunidades de base, en efecto, fueron un fermento idóneo que facilitó la masificación de la participación. El permanente trabajo de concientización, las redes de sociabilidad construidas a lo largo de los difíciles años de dictadura -su intimidad y confianza-, así como las estructuras organizativas forjadas en la necesidad y estrechamente conectadas con las organizaciones intermedias cercanas a la oposición, se convirtieron en un auténtico catalizador de la expresión social poblacional, canalizando sentimientos, emociones y reivindicaciones de un grupo mayoritario de pobladores a través de la movilización social. Es decir, fueron las redes organizativas construidas en la base, el canal preciso que convirtió el malestar en un movimiento social fuerte que instaló la creencia ampliamente compartida de derrocar a la dictadura a través de la acción colectiva.

En ese contexto, el grupo de salud de Beatriz, tuvo una labor destacada. No sólo ayudando a los cientos de heridos por la durísima represión policial que siguió a cada protesta, sino también por su trabajo de concientización que incentivó la expresión del descontento. "Si no fuera por ese apoyo que se les dio psicológico para buscar en sí misma los derechos como mujer, como persona (...), la gente no habría salido", señala Beatriz. Ciertamente, esta conciencia empoderó a los pobladores en su resistencia y reforzó sus convicciones sobre la necesidad del trabajo conjunto, "de todos, para hacer algo grande, perdurable".

Beatriz recuerda el atrevimiento con que encararon este periodo de protestas que las llevó a tomar iniciativas que iban más allá de las propuestas que las cúpulas opositoras proponían: "nosotras hicimos una marcha. Pa' la protesta, antes de tocar las cacerolas en las casas como nos habían dicho (...) La organizamos las mujeres de los distintos sectores poblacionales". Lo interesante de este recuerdo, es que las pobladoras pertenecientes al grupo de salud del sector entendieron la protesta como un momento especial y un modo adecuado por el cual expresar abiertamente el sentir respecto a la situación que les tocaba vivir.

Las protestas también evidenciaron el trabajo conjunto de un amplio espectro ideológico, que no distinguía entre comunistas, democratacristianos o simples opositores a 
Pinochet. En el barrio, el trabajo los incluyó a todas y todos, pese a las diferencias.

¡Éramos piquetes de 100200 personas! (...) En los piquetes había de todo. Entre medio, uno sabía quién era quien, pero ahí también lo hacíamos todos juntos. Ellos -señala Beatriz en relación a los grupos armados de las Milicias Rodriguistas - nos iban cubriendo, qué se yo. Usted sabe que los jóvenes iban más a la confrontación; a tirar piedras, a tirar bombas molotov, pero eso fue ya pal año $84,85^{19}$.

Esta masa movilizada, que daba pie para la acción pacífica pero también a actos de violencia, fue acusada de caer en el descontrol, el abuso de la fuerza y ser influenciada por los sectores violentistas que desvirtuaban el sentido de la movilización y, por tanto, al proceso de recuperación democrática (Aylwin 1998: 317). Beatriz, relativiza esas afirmaciones, insistiendo que, en la población, y concretamente en las marchas y protestas, la intención era participar y expresarse libremente. La violencia aparecía cuando llegaba la policía a reprimir cualquier intento de manifestación. Al respecto señala:

\begin{abstract}
Quién nos iba a guiar! La mayoría eran mocosos que conocíamos de así de chicos. Mire, si lo único que no nos gustaba, era que nos ocuparan las marchas que nosotros organizábamos con violencia, con molotov, cuando había mucha gente. Porque ahí tiraban balas los pacos nomás! Se hacían los mensos y disparaban nomás (...). Cuando empezó a aparecer la violencia, nosotras empezamos a buscar otras formas ${ }^{20}$.
\end{abstract}

Pero el proceso sociopolítico tomó otros rumbos tras el atentado a Pinochet. El abandono de la estrategia movilizadora también provocó un progresivo abandono de las iniciativas de base, a razón de encausar la disputa política exclusivamente por la vía institucional y alejar así a la disidencia de la izquierda y los movimientos

19 Entrevista realizada por el autor en septiembre 2014.

20 Entrevista realizada por el autor en septiembre 2014 armados que se desenvolvían con naturalidad entre la masa movilizada. De esta forma, se abandonó progresivamente el patrocinio a las organizaciones de base, sobre todo en aquellos espacios que habían alcanzado mayor autonomía respecto de las direcciones políticas y sociales. Beatriz, al respecto, señala que, pese a las advertencias, jamás dimensionaron la magnitud del giro que se estaba dando. Pero, la venida de Juan Pablo II, en 1987, encendió las alertas:

\begin{abstract}
Cuando vino el Papa, fue la madre de todas nuestras desgracias que han seguido. Queriendo mucho al Papa. Pero ahí fue el cambio de la Iglesia, a partir de esa instancia hubo el cambio (...). Que la iglesia de los pobres... ipa fuera, se fue al tacho!.. (...) Lo percibimos ahí [el cambio]. Si en una conversación que yo tuve con un seminarista, me dijo: no, si aquí nos cagaron a todos ${ }^{21}$.
\end{abstract}

En la parroquia y los distintos órganos intermedios también se evidenció este giro; curas, monjas y asistentes que habitualmente colaboraban con la base, fueron removidos y destinados a otras tareas cortando los lazos que se habían constituido a lo largo de los años. Lo más terrible, nos insiste en reiteradas ocasiones Beatriz, fue el desprecio que significaba esta nueva actitud y comportamiento hacia acciones y actividades que tanto había costado levantar y que tanto ayudaban a la comunidad.

Sentí y siento que más allá de lo material, fue tanto lo que se dejó tirao', tanto lo que se perdió; pérdida en el sentido humano, independientemente de lo material. Porque fue un saqueo. Para mí fue un saqueo. Entonces yo digo que ahí empezó todo... Tantas pérdidas, digo yo: por qué negociaron (...) Lo que nunca tenían que haber negociado! Ya habíamos logrado, alcanzado tantas cosas (...) [Por eso] Me sentí muy traicionada. La traición fue muy grande. A la gente. ¿Quién ganó todo? fue el movimiento social. (...) Y esa fue la herencia del complot que hicieron con los partidos políticos que disolvieron lo que se hacía

\footnotetext{
Entrevista realizada por el autor, diciembre 2012
} 
acá; disolver y decir que la política era esto y lo otro y dejar la política y las decisiones por allá; allá arriba y los de abajo, nada 22 .

Beatriz asumió que, tras el plebiscito y el retorno a la democracia, se confirmaba "la traición" al movimiento social: "Tengo una cuestión latente en el sentimiento interno de que nosotros desde que terminó la dictadura no había terminado, estábamos metidos en ella". El paso del tiempo sólo le ratificó esa sensación de profunda decepción, asumiendo que todo el esfuerzo realizado en aras de la comunidad fue en vano: "Yo me olvidé de todo para dedicarme de lleno a la comunidad, para sacar la piedra en el zapato. $Y$ no era una piedra, era un sistema. (...) pero era más que eso"23.

Un "sistema", político social y económico que se instauró en dictadura pero que "negoció" -en palabras de Bety - su proyección hasta hoy. Un sistema que aliena y subordina a las personas: "a las mujeres al consumo, a los hombres a las tarjetas, a los jóvenes a las drogas y la distracción banal. La conciencia se acabó. Y ahora la gente está pisando el palito, andan como zombis", nos dice. Al respecto, efectivamente responsabiliza a un sistema, pero no exime a su gente, señalando que "la gente se olvidó, (...) no tiene memoria. Como que se bloqueó. Por eso, cuando me toca hablar, yo siempre digo, a ver, vamos a hacer un poco de historia. (...) las señoras se molestan, pero es que si no conectamos el pasado con el presente, no tenemos nada"24.

\subsection{Del compromiso a la desafección. Memorias de un joven poblador socialista ${ }^{25}$}

Para el golpe de Estado, Jaime era estudiante, tenía 16 años y ya había empezado a participar en política cuando Allende fue electo presidente. En el Liceo Industrial de Gran Avenida -y al igual que en casi todo el país - el aumento de concientización política de la sociedad también había ocupado el espacio estudiantil, por lo que Jaime, desde los 14 años, experimentó una relación directa con la política militando en un partido. "Todo el mundo hablaba de política, se daba en todas partes (...). En los colegios estaban el núcleo de los comunistas, el núcleo de los socialistas, los del MIR. ¡Todos! Ahora no hay nada de eso. (...) Hoy ya día nadie quiere ser político", señala con una mezcla de entusiasmo y desdén. Ciertamente, los grandes proyectos de "planificación global" (Góngora 1998), propiciaron una fuerte politización de la sociedad, sobre todo en aquellos espacios que habían estado al margen de la vida política tradicional del país como el campo y los sectores populares urbanos. El fenómeno respondió a las estrategias de izquierda-y más tarde la DC- por copar electoralmente estos espacios, pero, sobre todo, por la irrupción de los sectores populares a través de distintos movimientos sociales a lo largo de todo el siglo XX (Garcés 2004). Por su parte, desenvolverse políticamente en "la comuna roja" como era identificada San Miguel por esos tiempos, dada la injerencia que la izquierda tuvo en los barrios obreros del sector sur de Santiago, permitía a sus habitantes acceder a una amplia gama de posibilidades políticas, formativas y culturales que ofrecían las Juventudes de los

Las entrevistas personales con Jaime Pérez fueron tres y se realizaron entre diciembre de 2014 y julio de 2015 . 
partidos obreros (Winn 2013: 39). Este afán transformador y el progresivo proceso de politización de la sociedad -en una comuna identificada con la izquierda-, marcaron profundamente el modo de entender el mundo de nuestro entrevistado, así como ocurrió con muchos otros en los sectores populares urbanos de Santiago.

Jaime, pertenecía a la Juventud del PS y su labor estuvo supeditada al mundo estudiantil. A través del colegio y los contactos con otras instituciones escolares discutía y reivindicaba los temas concernientes al ámbito sectorial. Ahí accedió a una contundente formación ideológica que le permitió insertarse en el trajín cotidiano de la acalorada discusión política de esos años. Sin embargo, señala, esto cambió abruptamente tras el golpe.

La situación es bien brusca. Lo primero, veníamos de una situación fantástica, todo era felicidad. Un arcoíris real, no el que después nos vendieron y donde existían organizaciones fuertes como la CUT, o los Comandos industriales y todos estábamos participando ${ }^{26}$.

La discusión dio paso al silencio absoluto, cuando se decretó el receso político. La persecución política vino acompañada de la intervención militar en la dirección de los establecimientos educacionales, como sucedió en el Liceo de Jaime. La nueva situación, terminó con cualquier tipo de actividad política. Lo que quedaba era la reclusión o la clandestinidad.

En ese contexto, los jóvenes que decidieron combatir a la dictadura, debieron asumir la militancia del partido y "aguantar lo que se vino; formar la redes, generar las condiciones para formar un partido nuevo". Pasado los

26 Ibíd primeros meses del golpe, Jaime colaboró en la reconstitución del partido en la base, en esos momentos fragmentado por la persecución, detención o/y exilio de sus miembros. Esto lo obligó a postergar sus estudios y pasar a la clandestinidad. Su labor fue reunir a antiguos militantes, conectar y reorganizar las redes socialistas en todo el sector sur, de modo de dar la batalla contra la naciente dictadura. "Había que luchar", dice; no se conformaban con la nueva situación. La labor era sumamente compleja. Los esfuerzos por reconstituirlo se hacían de maneras bien "artesanales", tanto porque escaseaban los recursos como porque había muy poca gente para semejante tarea. "La Cisterna antes era bien amplia. Todo el sector sur era inmenso (...) y había que hacer largos recorridos a pie, a lo más en bicicleta, lo que dificultaba la labor ${ }^{27}$.

A pesar de las dificultades, sus convicciones resultaron ser sólidas y fueron, en estos momentos de estrechez y peligro, el sustento de su accionar comprometido, a riesgo de perder la vida. No hay que olvidar que el perfil sociodemográfico de las víctimas de la represión establecido por la Comisión Nacional de Verdad y Reconciliación (CNVyR, 1991), señala que eran jóvenes, menores de 30 años, militantes de los partidos de la Unidad Popular o el MIR, trabajadores y campesinos. Es decir, Jaime calzaba perfecto en el perfil de potencial víctima de la dictadura; tenía entre 16 y 20 años mientras se realizó la purga más dura ejecutada por la DINA; era militante socialista y poblador del sector sur. No obstante estar consciente de esta cuestión y pese al peligro que representaba su tarea, se sentía seguro por estar haciendo lo correcto "lo que había que hacer", como nos

\footnotetext{
Entrevista realizada por el autor en diciembre de 2014
} 
menciona en más de una ocasión. Convencido y en paz porque lo movían sus ideales.

Nosotros en esa época estábamos muy imbuidos de todo lo que era la Revolución Rusa, Vietnam, Cuba principalmente, entonces ahí hay algo que, desde el punto de vista ideológico uno tenía adonde acercarse. Hoy día no tienes nada. Independiente de si esos supuestos eran falsos, tenías una idea, un árbol adonde arrimarte. Que hoy no lo hay. (...) Eso permitía que desde el punto de vista político la gente estuviera muy conectada con lo que había que hacer ${ }^{28}$.

Los esfuerzos en el sector comenzaron a dar frutos, permitiendo diversificar las tareas. Jaime se empezó a encargar de distintas labores logísticas entre las que destaca una particularmente simbólica. "Por el miedo, la gente empezó a botar sus libros ¡bibliotecas enteras! Y nosotros las trasladábamos jen micro! en los bolsos llevábamos a todos los profetas: Lenin, Marx, Engels. (...) Mientras algunos los quemaban, nosotros los rescatábamos", señala con nostalgia y orgullo.

El rescate de estos clásicos marxistas se convierte en un símbolo para la memoria de Jaime. La interrupción violenta de un proyecto político como el de la Unidad Popular, que había convertido en protagonistas a los sectores populares, no podía echar por tierra las bases en las que se sustentaba el gobierno; el pensamiento marxista. La necesidad de levantarse y combatir a la dictadura desde el socialismo -"el de verdad, "no como el de ahora", nos repite- va a ser una convicción que dirigió su accionar durante esos 17 años, postergando proyectos personales en pos de su consecución. Para él, la sola idea de restituir la democracia estuvo siempre estrechamente relacionado con la restauración del proyecto democrático de la UP, cuestión que ya estaba siendo cuestionada en la dirección del partido ${ }^{29}$.

Algo más afianzada la labor de reconstitución del partido, se inició la tarea para extender las redes. Las tareas de Jaime, en tanto, pasaron a orientarse a empoderar las redes organizativas de base creadas para paliar los efectos de las políticas de shock. En esa línea él y sus compañeros comenzaron a colaborar en distintos grupos, de manera de dar fuerza a la sociedad civil. Algunos se orientaron en el trabajo de base, otros a potenciar el trabajo sindical:

Claro, nos tocaba empezar a hacer movimiento social en la población. Era como por el año 78. (...) Y ahí estuve vinculado a varias organizaciones; a los sin casa, el comité de vivienda como le llamaban, (...) también comités de Derechos Humanos, y en otros más, además de la pega en el partido ${ }^{30}$.

En efecto, la reactivación de las redes partidistas en el micro espacio social, conectó a los partidos con las organizaciones de base. Comunistas, socialistas, el MIR y democratacristianos, progresivamente, comenzaron a repolitizar las iniciativas creadas en pos de la subsistencia. En ese sentido, Jaime enfatiza que sin el trabajo de base de los partidos políticos, la repolitización habría sido imposible, sobre todo porque establecieron referencias claras, precisamente cuando la dictadura hacía todo el esfuerzo por desarticular y despolitizar a la sociedad.

\section{La gente que logró reconstituir toda esta cosa, éramos a la}

29 Mientras Jaimearriesgalavida por Marxo Lenin, sus correligionarios del exterior cuestionan la teoría clásica aproximándose a Antonio Gramsci, pensador guía de la renovación socialista, en momentos que en Europa era el referente de los principales exponentes del Eurocomunismo (Arrate, Rojas, 2003: 223).

30 Entrevista realizada por el autor en marzo de 2015. 
vez militantes de partidos. Fue (...) una simbiosis. Estaba la gente, pero, sin los partidos, tú no habrías podido tener la dirección hacia donde querías enfocarte. (...) ni la idea de lo que había que elaborar. Y eso se logró, digamos, en conjunto con el partido. Justo lo contrario de lo que pasa hoy día: la sociedad chilena está huérfana. No tiene (...) alguien que la dinamice y le genere (...) orientación política $^{31}$.

La "simbiosis" de lo social y lo político resultó vital para ampliar la politización a partir de los años 80' (Valdés 1986), representando un resurgir de la acción contestataria. En ese orden, Jaime participó en el trabajo comunitario, aunque sin figurar, al seguir teniendo responsabilidades internas, dedicándose a problematizar la situación de las organizaciones y de la sociedad general, de manera "ir creando conciencia", señala. Por ejemplo, recuerda la ardua labor que realizaron en los clubes deportivos del sector, a fin de acceder a los jóvenes y arrastrarlos a la causa.

Los clubes deportivos, después [del golpe] fueron tomados por gente bien de derecha. Pero nosotros nos fuimos metiendo de a poco nomás. El trabajo hormiga, que le llamábamos. (...) Y fuimos generando espacios culturales, donde hacíamos peñas, trayendo compañeros para que hicieran obras de teatro y esas cosas. (...) Nosotros siempre intentamos realizar una discusión en buena con la gente, para que permitieran abrir los espacios (...). Eso permitía que tú pudieras conversar con ellos y dialogar 32 .

Las actividades realizadas proyectaron imágenes de un pasado mítico: el de la Unidad Popular y el tiempo pre-dictatorial. La música de Violeta Parra, de Víctor Jara ${ }^{33}$, entre otros, o películas y documentales de contenido político-cultural prohibido, fueron símbolo y

lbíd.

32 Entrevista realizada por el autor en julio de 2015.

33 La aparición de Víctor Jara, torturado y asesinado fuera del Cementerio Metropolitano límite de la Población Santa Olga, estableció un nexo emotivo del sector con la figura del cantautor chileno. (ICNVyR, Tomo I: 130). a la vez sustento de esta acción organizativa. Igualmente, la colaboración de las entidades externas fue fundamental. Las dificultades logísticas en un ambiente de suma escasez sólo podían ser medianamente paliadas por la cooperación externa.

\footnotetext{
Todo lo conseguías a través de los partidos. Hablaba con el compañero: iya, perfecto, les mandamos unos compañeros que están estudiando guitarra! (...) Y ahí armábamos unos talleres de Guitarra o peñas y claro, tocábamos de todo. (...) Pero puta, costaba... no sé, traer una cuestión de cine, ¿cachai? Esas cosas era difícil conseguirlas. Pero así te agarrabai a los cabros (...) porque las traías cosas que ellos no veían. Me acuerdo que cuando empezó a salir la información de Nicaragua, aquí no daban ná, estaba todo prohibido, y la gente no tenía idea. Entonces nosotros empezamos a traer ese tipo de películas y (...) la gente quedaba alucinando ${ }^{34}$.
}

La revolución sandinista, ciertamente, se convirtió en un símbolo que la izquierda chilena utilizó para esperanzar a la población en el combate a la tiranía. La experiencia de los militantes que combatieron en Centroamérica, jugó un papel fundamental en la reactivación de los movimientos armados (Rojas 2011: 109). En las poblaciones, la imagen de la revolución triunfante despertó ilusión y esperanza entre la juventud que "quedaba súper enganchada con eso que veía y empezaban a querer participar. (...) era alucinante ver todo eso, que el pueblo derribaba una dictadura", recuerda.

Conocida es la relevancia que van a tener los jóvenes en el mundo poblacional durante las protestas, donde su acción contestataria marcó una auténtica "cultura de barricada" (Stern 2013: 333), que cuestionó, sin grandes fundamentos, pero con una decisión total, el orden vigente

34 Jaime, no obstante, enfatiza que pese a este apoyo venido de fuera, la financiación de "la cosa política" se logra de las actividades que realicen para obtener fondos. (Carcajadas). Entrevista realizada por el autor en julio de 2015. 
a través de la acción. Desde sus distintas identidades van a reapropiarse del espacio público; la dualidad de rabia y compromiso, rebeldía y exclusión se combinó con los distintos ámbitos -escindidos- desde donde los jóvenes visibilizan su descontento. "La juventud como intento" (Agurto et. al. 1985), va a manifestar la expresión -siempre parcial- de aquellos esfuerzos por superar los efectos que el poder despliega en ellos a través del disciplinamiento y la exclusión. La violencia juvenil se convirtió en un símbolo de la propia identidad juvenil: rabia incontenible, sin posibilidad de canalizarse en algo específico o útil. De ahí que algunos (Tironi 1987), hablen de anomia, aunque más bien, retrate la frustración de una generación. Es cierto, esto no podría extenderse al conjunto de los jóvenes pobladores, pero, no obstante, representó una acción distintiva y que, de algún modo, evidenciaba los efectos de la revolución social en curso y el enorme desarraigo que va a invadir a amplios sectores de la juventud.

Jaime observa y reconoce este proceso, pero no se siente parte de él ya que asume estar en otra vereda generacional, aquella que sí se formó ideológicamente y a partir de esas convicciones trazó un proyecto que orientó su acción. En los jóvenes de los 80' no ve esto, y resulta difícil orientar el ímpetu juvenil hacia su causa:

\footnotetext{
Hay dos cosas. Todo lo que logra la dictadura con respecto a la cosa política. (...). Lo otro, es que los compañeros, los cabros jóvenes, son un poco reacios a mantener cierta disciplina y a participar de la educación política. (...) Así tratábamos de llegar a ellos y formarlos. Pero era difícil. (...) Como te decía, los cabros querían puro combatir, salir y darle cachai', entonces era difícil ${ }^{35}$.
}

Las protestas van a explicitar esta trama social, organizativa y contestataria. La convergencia y

\footnotetext{
Entrevista realizada por el autor en julio de 2015.

unidad que existió con los otros partidos a la hora de organizar la defensa de las poblaciones del ataque policial es quizás el hecho más distintivo de sus recuerdos:

\begin{abstract}
Las acciones que se hacían principalmente estaban dadas por vincularse primero con los partidos políticos por arriba. En términos en que uno iba a conversar con el encargado político del PC, te juntabai con el del MAPU, el MIR. Y generábamos la mesa de encuentro y de distribución de acciones y entonces ahí te comprometías con lo que ibas a hacer. Y ahí uno comprometía todo el aparato logístico que uno podía tener. $Y$ te generaba así las acciones ${ }^{36}$.
\end{abstract}

Jaime destaca la fuerza y autonomía que alcanza la movilización social haciendo evidente el proceso de rebeldía que vive el mundo poblacional. Un hecho emerge por sobre todos cuando recuerda momentos emblemáticos durante las protestas; un acontecimiento grabado en su memoria y en la memoria colectiva de la disidencia; la muerte del sacerdote André Jarlan. La emoción de este episodio se relaciona a la incredulidad que aún despierta en su memoria, el desafío pacífico- que el pueblo logra en esta ocasión. La violencia en 1984 ya estaba desatada en las poblaciones y "el baleo al aire" para hacer caer a cualquiera -incluso un sacerdote- ya se había extendido en la práctica policial (Moulian 1997: 292). Es decir, la expresión de esos miles de pobladores, implicaba arriesgar la vida. Pero eso no importaba. El impacto de la muerte de un sacerdote de población, estrechamente conectado con la gente -estaba a cargo de los grupos de jóvenes alcohólicos y drogadictos de La Victoria- provocaron tal conmoción en el sector, que sus habitantes superaron el temor y marcharon, haciendo vigilias hasta que Jarlan fue enterrado. La frustración tomaba 
otros canales y se expresaba en un canto por la vida que rechazaba esa cultura de violencia y muerte:

En esos momentos, era de noche, toque de queda, y las poblaciones se volcaron allá. Salieron nomás, les dio lo mismo todo. Es que el momento fue.... Todas las poblaciones se volcaron, de todos lados! Y nos vinieron a allanar acá y nosotros íbamos hacia allá. Eso fue lo más increíble, o sea, como te digo estábamos en toque de queda (...) Pero la gente igual salió. Todo el mundo prendiendo velitas. Fue una hueá espectacular. Yo no sé si tú fuiste al Museo de la memoria adonde están los desaparecidos que está lleno de velas ... así mismo se veía el caminar por las calles (...) jhasta allá mismo! Todas las poblaciones se volcaron a las calles, cachai!. Y los milicos, no pudieron dar la orden de matar. Entonces, fue espectacular, excepcional, la movilización social que se logró esa noche ${ }^{37}$.

La conexión de esta vigilia permanente tras la muerte del sacerdote francés con el Museo de la Memoria, sintetizan de algún modo el lugar de este suceso emblemático queda registrado en la memoria de Jaime. Un episodio que viene a reconocer nuevamente el papel del pueblo en su desafío al régimen, desmontando momentáneamente su aparato represor. Un acontecimiento que evidencia los límites que la gente más humilde va a poner a la dictadura, saliendo y velando en el espacio público a una víctima del régimen. Ése, señala, "era el verdadero No", el no de la gente, del pueblo. "Nada que ver con el otro No cachai, que fue todo un invento" (en referencia al plebiscito).

Esta comparación, entre la vigilia pública a Jarlan y el museo de la memoria, entre el "no poblacional" y el no electoral, confrontan las actitudes del pueblo y sus dirigentes. En otras palabras, Jaime ve en ese recuerdo la expresión potencial del pueblo, pero al mismo tiempo la identifica como un artefacto de museo; es

\footnotetext{
Entrevista realizada por el autor en marzo de 2015.
}

un recuerdo de algo que ya no es, en alusión al compromiso y fuerza del movimiento social desechado por la democracia.

Pero las protestas van a simbolizar para Jaime la primera manifestación de los cambios estratégicos a nivel de partido que terminaron por dividir al socialismo y más tarde a la oposición. Si bien el proceso de reflexión teórica que vive su partido, se produjo a fines de los 70’ entiende que sólo cobró relevancia práctica en 1983. En efecto, la necesidad de llegar a acuerdos y establecer alianzas que unieran a la oposición distanciándose del PC y la violencia, van a materializar el giro del partido hacia la moderación: "ahí se pusieron muy pesaos, si no rebajabas el discurso si no moderabas los puntos, (...) no se aliaban contigo. Y ahí la DC jugó un papel muy importante", insiste. Sin embargo, el éxito de las protestas, así como la unidad en la base, postergó las diferencias, al menos durante este periodo de "ebullición" (Moulian 1997: 288).

Pero el aumento de la violencia y cierto estancamiento de la movilización desde el punto de vista político, ampliaron las brechas al interior de la oposición. Progresivamente, como ya señalábamos, el movimiento social comenzó a disgregarse y la acción de resistencia de las bases a dejar de ser útil para los propósitos de la oposición moderada, generándose un paulatino distanciamiento ahondado por el ya señalado proceso de autonomía de las organizaciones de base.

Mira, esa diferenciación se empieza a dar posterior al año 85-86. (...) Ahí es donde se genera el vuelco (...) donde se va deteriorando el discurso. Ahí tú llegas al año 86 , y bueno, el año 87,88 ves que el discurso se fue a la mierda. (...) Y otra vez fuimos traicionados, porque no es la primera traición que tenemos; fuimos traicionados el 
73', volvemos a ser traicionados en los 80', volvemos a ser traicionados en los 90'. Y pa' qué decir después, la traición es constante ${ }^{38}$

Es relevante la utilización del concepto de 'traición' con que Jaime retrata el giro de la oposición moderada tras el atentado a Pinochet. Con el fracaso de la vía militar y la fractura de la oposición, se consolida "la vía electoral", que marca la derrota según Jaime, marcando y redefiniendo hasta hoy los recuerdos de ese pasado. De hecho, Jaime permaneció activamente vinculado al PS hasta el año $87^{\prime}$ cuando sentirá que ya todo había cambiado y el partido en el que alguna vez militó se había acabado.

El partido va a sufrir el desmembramiento constante. $Y$ se fueron generando fracciones. Yo terminé en la fracción comandante. Hasta que dije, puta, comandante, no comandamos nada, no somos ejército popular, tamos puro hueviando, chao. Y eso lo dijimos varios... políticamente, con documentos. (...) Y lo otro ya era puro bluff. Felipe González y todos los de acá vinieron a quitarle la filosofía, leninista del partido, eso ya no era socialismo no en el que me formés9.

Esta representación del proceso permite comprender cómo va a entender la historia de ahí en más. "La derrota", como él mismo señala, marcó los destinos del país al legitimar la normativa de la dictadura. Pero lo más duro, fue el olvido que impusieron respecto a lo que realmente había ocurrido durante esos años, "porque la fuerza de todo lo hizo el movimiento social". Por eso Jaime entiende que el proceso de instalación incluido el plebiscito de 1988, sepultó un proyecto alternativo, distinto a lo que finalmente se impuso, y que falseó la historia de esos años.
Han querido cambiar la cosa y ahora dicen que el No cambió todo y sabemos que no es tan así. Me gusta hacer énfasis con esto porque te bombardean los medios de comunicación, en la tele, que es así y no, no fue así. Y molesta. Molesta (...) porque eso desconoce de todos los compañeros muertos, léase del partido que sea, de toda la gente que se torturó y todo lo que sufrimos los mismos chilenos, porque todo eso se desconoce, ¿cachai? Nadie habla de cuando nos acorralaban militarmente. Porque no fue una sola vez, sino constantemente, y cada vez que había una protesta y generábamos una barricada y salíamos a pelear, y estábamos rodeados e incomunicados y eso nadie lo dice. Entonces, parece que, claro, con el No, esta hueá se acabó, nadie más sufrió, todo el mundo feliz, y no, no fue asít ${ }^{40}$.

De esta forma, entiende que el plebiscito acabó con la resistencia y el trabajo que él y muchos de sus compañeros realizaron por un proyecto político, con ideas más o menos específicas de lo que debían ser los pilares de una nueva democracia. En ese sentido, la Unidad Popular y el proyecto allendista seguirán copando el imaginario de Jaime, que sufrió una derrota definitiva con el plebiscito de 1988 y la instauración de la democracia:

La salida que se estaba dando no era la que nosotros queríamos y sabíamos que lo que venía no era lo que se necesitaba. (...) Eso, es lo que hoy en día a mí me ha servido para saber que sí tenía la razón. Desde el punto de vista político, desde el punto de vista ideológico. No nos vendieron la pomá' como se la vendieron a todo Chile. A todo el pueblo. (...) Lo dijimos, la vamos a pasar mal (...) fuimos derrotados, no asumimos esa derrota. $Y$ eso es lo que nos ha tenido más engañados ${ }^{41}$.

\section{Hacia una hermenéutica de la memoria disidente en la lucha por la democracia (a modo de conclusión)}

La "diversificación de los referentes sociales" que representaron las protestas nacionales

\footnotetext{
$40 \quad$ Ibíd

41 Ibíd.
} 
(Stern 2013: 328), sitúan a Jaime y Beatriz como íconos de ese pasado. Qué ocurrió con estos personajes una vez terminada la dictadura y por qué han elaborado sus memorias con acentos críticos y una evidente desesperanza, manifiestan la ruptura que experimentó la oposición al régimen entre las cúpulas partidistas y un sector considerable de la sociedad respecto a los fundamentos que debían sostener a la nueva democracia. En ese sentido, las concepciones minimalistas impuestas al interior de la oposición, significaron una derrota para miles de pobladores comprometidos en la movilización social. La transición significó pues, abandonar prácticas y formas específicas de acción política, fuertemente arraigadas en el imaginario colectivo de sus actores y vinculadas al proyecto democrático y popular que encabezó Salvador Allende. En ese contexto, las memorias de Jaime y Beatriz, tienen que ver no tanto con los hechos en sí, sino con su significado en el tiempo. La falta de decisión por desmontar la herencia normativa dictatorial cuando la democracia ya estaba consolidada, conecta el sentimiento de traición al plebiscito de 1988. Ahí está el nodo central que define y resignifica pasado y presente para nuestros entrevistados.

Los elementos que constituyen a Beatriz como símbolo de la disidencia en los años 80', son fundamentalmente su condición de mujer, habitante de los márgenes y su ferviente compromiso por la organización comunitaria donde la solidaridad se constituyó en un aspecto esencial de su práctica. Ámbitos que definen buena parte de su accionar a lo largo del tiempo. También los marcos en que sustentará sus recuerdos y, por tanto, la forma en que delineará su memoria. Como pobladora, conoció de cerca la experiencia emancipadora que representaron las tomas de terrenos en su lucha por la casa propia. La organización de los primeros vecinos de Santa Adriana sirvieron de base para su noción de comunidad. Dicha experiencia desplegada en un contexto político e ideológico específico -el del Estado de compromiso - conformó un acervo cultural que delineó su pensar y proyectó en su imaginario los valores de la democracia, la participación y la comunidad solidaria como elementos constitutivos de su accionar.

Por su parte, Beatriz logra emanciparse de los yugos que impone culturalmente el sistema patriarcal que impera en las sociedades latinoamericanas. Su formación, su experiencia laboral así como su inquietud vital, la llevaron confrontar no sólo los patrones identitarios que impone la dictadura -como madre, dueña de casa y responsable de reproducir el orden vigente- (Valdés 1987: 10), sino de toda una tradición. Su liberación definió su trayectoria y ayudó a la construcción de un modo de ser-pensar, que la enorgullecen y empoderan como ciudadana. Ello ineluctablemente está asociado a una época específica de su vida, donde se desenvolvió en plenitud. Dicho de otro modo, su liberación como mujer, la autonomía de las organizaciones en las que participa, el alto grado de solidaridad y el carácter democrático y paritario que alcanzan éstas a nivel interno, proyectan sus logros hacia un modelo específico de democracia. Estos marcos entrarán en tensión con los valores que se imponen en la nueva democracia; de ahí su rabia por el abandono de una forma valiosa de práctica democrática. Por eso su desconsuelo con la sociedad actual: narcisa, consumista y extremadamente desigual.

En la memoria de Jaime, en tanto, se observa la existencia de un elemento referencial que 
marca define y articula, buena parte de su relato sobre el pasado reciente. La bisagra que separa y a la vez conecta pasado y presente, que funciona como eje en la elaboración de sus recuerdos. El nodo que marca su memoria, sitúa al proceso de instalación en el marco normativo autoritario como centro desde el que se otorga sentido a su práctica como actor social, pero que también conecta dicha experiencia con la realidad general que vive el país. Desde esta perspectiva, el giro que vive la oposición desde la movilización social a la electoral, representó un registro histórico que marca un punto de inflexión que, en su caso, se materializa con la renuncia al Partido en que había volcado sus esperanzas, anhelos y esfuerzos por transformar la realidad. Esa renuncia simboliza la derrota y el término de su lucha, certificando el fin de una etapa para dar paso a una nueva era en la que sus valores ya no son compartidos.

Es de algún modo, como si el pasado dictatorial hubiese sido enterrado por un presente casi atemporal, ya que sigue "siendo" en la reproducción de Jaime- que se extiende inalterable y todopoderoso desde la derrota del movimiento social a fines de los 80 ' hasta hoy. En Jaime, por tanto, se observa de manera locuaz, una memoria que asume la derrota y la traición, responsabilizando a ésta por los problemas del Chile actual. Si Moulian señaló que entendía a Chile, ese de 1997 cuando escribe, como una producción del Chile dictatorial, es decir, una fotografía de una imagen autoritaria (Moulian 1997: 15), las memorias de Jaime, nos sitúan desde una perspectiva similar -pero desde abajo- en el mismo proceso para señalarnos: si los valores de la dictadura se impusieron y proyectaron a la democracia, fue porque las cúpulas políticas de la oposición lo legitimaron, tomando como suya la herencia dictatorial que representó el sistema económico que dirigió todos los ámbitos sociales y culturales de la naciente democracia, en desmedro de la acción y participación ciudadana. De una auténtica democracia. Sólo así se explica Jaime la traición. Y la decisión de desmovilizar, despolitizar y desincentivar a todas las redes de sociabilidad que se venían desarrollando en el mundo poblacional chileno y que se encontraban en franco proceso de emancipación. Esta cuestión, también evidencia el dolor por la derrota, por la falta de reconocimiento a su labor, y el término de un proyecto que delimitó y estructuró los principios y valores que rigieron la acción política de Jaime durante buena parte de su vida.

\section{Bibliografía}

Agurto, I., Canales, M. y de la Maza, G. 1985. Juventud chilena: razones y subversiones. Santiago: ECO, FOLICO, SEPADE.

Álvarez, R. 2011. Arriba los pobres del mundo. Cultura e identidad política del Partido Comunista de Chile entre dictadura y democracia 1965-199. Santiago: LOM ediciones.

Arrate, J. y Rojas, E. 2003. Memoria de la izquierda chilena. Tomo II (1970-2000). Santiago: Edicines B. Grupo Z.

Aylwin, P. 1998. El reencuentro de los demócratas. Santiago: Ediciones b.

Bastías, M. 2013. Sociedad Civil en dictadura. Santiago: Universidad Alberto Hurtado.
Bianchini, Ch. 2012. Chile, memorias de La Moneda. Madrid: UAM- IEPALA.

Boeninger, E. 1997. Democracia en Chile. Lecciones para la gobernabilidad. Santiago: Andrés Bello.

Bruey, A. J. 2009: "Neoliberalism and Repression in poblaciones of Santiago de Chile". Stockholm Review of Latin Americans Studies, 5, pp. 17-27.

Campero, G. 1986. "Luchas y movimientos sociales en la crisis: ¿se constituyen los movimientos sociales en Chile?". En F. Calderón, Los movimientos sociales ante la crisis. pp. 289-307. Buenos Aires: Clacso-UNU. 
Cavallo, A. 1997. La historia oculta del régimen militar. Santiago: Grijalbo.

Grupo de Educación y Recreación "Las Patotas", 2012. "Tres historias locales que reflejan la historia social de una época. Santa Adriana". En: Garcés M. Villela H. (eds.) La persistencia de la memoria popular. Historias locales Historias de Vida. Santiago: Educación y Comunicaciones, ECO.

Cuesta, J. 2008. La odisea de la memoria. Historia de la memoria en España en el siglo XX. Madrid: Alianza.

Garcés, M. 2002. Tomando su sitio. El movimiento de pobladores 1957-1970. Santiago: LOM.

2004. "Los movimientos sociales populares en el siglo XX. Balance y perspectivas". Política No 43 , Primavera. Universidad de Chile: Santiago.

Garretón, M. A. 2010. «La democracia incompleta en Chile: la realidad tras los rankings internacionales.» Revista de Ciencias Políticas Vol. 30, N 1, pp. 115-148.

1995. Reconstruir la política. Transición y consolidación democrática en Chile. Santiago: Andante.

Geis, I. 1983. "La política al rojo vivo". Análisis, № 57. pp. 4-7.

Guillaudat, P. y Mouterde P. 1997. Los movimientos sociales en Chile 1973-1993. Santiago: LOM.

Góngora, M. 1998. Ensayo sobre la noción de Estado en Chile en los siglos XIX y XX. Santiago: Universitaria.

Hardy, C. 1986. Hambre + dignidad = ollas comunes. Santiago: PET.

Herreros. J. 1991. Escuché sus gritos. Santiago: Ediones Mosquito.

Lagos, R. 2012. Así lo vivimos. La vía chilena a la democracia. Santiago: Taurus.

Lünecke, A. 2000. Violencia política en Chile 1983-1986. Santiago: Arzobispado de Santiago.

Morales, E., 1983. Políticas sociales y sistema polítco. Antecedentes, situación actual y perspectivas. Santiago: FLACSO. Documento de trabajo $\mathrm{N}^{\circ} 188$.

Mouffe, Ch. 2007. En torno a lo político. Buenos Aires: F.C.E.

Moulian, T. 1997. Chile actual: anatomía de un mito. Santiago: LOM.

Perotin-Dumon, A. (dir.) 2007. Historizar el pasado vivo de América Latina. www.historizarelpasadovivo.cl. (Consultado en noviembre de 2016)

Portelli, A 1989. "¿Historia oral? Historia y memoria: la muerte de Luigi Trastulli”. Historia y Fuente Oral, $\mathrm{N}^{\circ} 1$. Barcelona. pp. 5-32.

Riquelme, A. 2009. Rojo atardecer. El comunismo chileno entre dictadura y democracia. Santiago: Centro de Investigaciones Barros Arana. DIBAM .

Rojas, L. 2011. De la rebelión popular a la sublevación imaginada. Antecedentes de la Historia Política y Militar del Partido Comunista de Chile y el FPMR. 1973-1990. Santiago: LOM.

Salazar, G. 2006. Violencia Política Popular en las grandes alamedas. Santiago: LOM.
Stern, S. 2013. Luchando por mentes y corazones. La batalla de la memoria en el Chile de Pinochet. Libro dos de la Caja de la memoria del Chile de Pinochet. Santiago: Ediciones UDP.

2009. Rercordando el Chile de Pinochet. Libro I de la trilogía, La Caja de la memoria del Chile de Pinochet. Santiago: Ediciones UDP.

Subercaseaux, B. 2010. "Historia de las ideas y la cultura en Chile e Hispanoamérica. un enfoque en torno a los Bicentenarios". Historia del Presente. Madrid. pp. 111-119.

Tarrow, S. 2006. El poder en movimiento. Los movimientos sociales, la acción colectiva y la política. Madrid: Alianza $\left(2^{\circ}\right.$ edición).

Tironi, E. 1987. "Marginalidad, movimientos sociales y democracia". Revista Proposiciones 14. Santiago: Sur.

Valdés, T. 1987. Las mujeres y la dictadura militar en Chile. Santiago, Material de Discusión, № 94. Santiago: FLACSO.

1986. El movimiento poblacional: la recomposicón de las solidaridades sociales. Santiago, Documento de Trabajo $\mathrm{N}^{\circ}$ 283. Santiago: FLACSO.

Winn, P. 2013. La revolución chilena. Santiago: LOM.

\section{Documentos}

Colectivo Caro-Ochagavía (1982-1987). El Portavoz. Boletín informativo. Santiago: Archivo Nacional de la Administración. ARNAD. Fondo de Organizaciones Sociales.

Corvalán, L. 1983. "No demorar un día más la unidad". Partido Comunista de Chile, Boletín del exterior (58). Santiago.

Informe Nacional de Verdad y Reconciliación 1991. 3 Tomos. Santiago: Ministerio del Interior. Gobierno de Chile.

Lagos, R. 1983. "Chile: los grandes temas y las tareas de la reconstrucción". Santiago. Discurso en el Teatro de la Comedia como presidente de la Alianza Democrática.

Valdés Subercaseaux, G. 1983. "Ahora es cuando". Discurso pronunciado por Gabriel Valdés en el Círculo Español de Santiago. 6 de Agosto de 1983. Socialismo y participación. Santiago.

Vicaría de la Vicaría de la Solidaridad 1982. Informe sobre Comedores Populares de la Vicaría de la Solidaridad. Evaluación y conclusiones. FDyAVS

1983-1986. Informe Mensual Santiago, Arzobispado de Santiago.

VV.AA. 1983. Manifiesto Democrático. Santiago, Archivo Histórico Gabriel Valdés (AHGV). Online. www.ahgv.cl

\section{Entrevistas Personales}

Entrevistas a Beatriz Sepúlveda, octubre de 2011 y diciembre de 2014.

Entrevistas colectivas, Taller para el Adulto Mayor, Centro de Acogida Santa Adriana. Marzo-septiembre 2015.

Entrevistas personales a Jaime Retamal entre diciembre 2014 y julio 2015. 
